\author{
Г.О. Скрябин ${ }^{1}$, А.В. Комельков ${ }^{1}$, П.Б. Копнин ${ }^{1}$, И.И. Никишин ${ }^{2}$, С.А. Кузьмичев ${ }^{1}$, Е.М. Чевкина ${ }^{1}$ \\ ${ }^{\prime}$ НИИ канцерогенеза ФГБУ «Национальный медицинский исследовательский центр онкологии имени Н.Н. Блохина» \\ Минздрава России; Россия, 115478 Москва, Каширское шоссе, 24, стр. 15; \\ ${ }^{2}$ ФГБОУ ВО «Московский государственный университет имени М.В. Ломоносова»; Россия, 119234 Москва, \\ Ленинские горы, 1, стр. 12
}

К о н т а к ты : Елена Максимовна Чевкина tchevkina@mail.ru

\begin{abstract}
Введение. Данные исследований последних лет свидетельствуют о том, что белки, входящие в состав липидных рафтов, могут быть задействованы в формировании экзосом и отборе белков, входящих в состав экзосомального карго. Такие данные получены для флотиллинов, структурно-функциональных компонентов плоских рафтов. Для кавеолина-1 (Cav-1), основного компонента кавеолярных рафтов, показано присутствие в экзосомах некоторых опухолевых клеток, однако его возможное участие в регуляции белкового состава экзосом ранее не исследовалось.

Материалы и методы. Нокдаун Cav-1 проводили методом трансдукции лентивирусного вектора, экспрессирующего предшественников малых шпилечных рибонуклеиновых кислот к Cav-1. Экстраклеточные везикулы (ЭКВ) выделяли из клеток линии Н1299 немелкоклеточного рака легких методом дифференциального ультрацентрифугирования. Препараты ЭКВ верифицировали с помощью трансмиссионной электронной микроскопии (анализ размера и морфологии) и методом анализа траекторий движения наночастиц (среднеразмерное распределение и концентрация). Для анализа экзосомальных маркеров и Cav-1 в клетках и ЭКВ применяли метод иммуноблоттинга.

Результаты. Анализ влияния экспрессии Cav-1 на состав белков ЭКВ, ассоциированных с биогенезом экзосом, выявил снижение уровня Alix и TSG101, повышение уровня белков липидных рафтов и отсутствие изменений уровня тетраспанина CD9.

Заключение. Полученные данные демонстрируют Cav-1-зависимое изменение состава ЭКВ, свидетельствующее об изменении соотношения везикул, образованных с помощью различных молекулярных механизмов.

Ключевые слова: экзосомы, липидные рафты, флотиллин, стоматин, кавеолин-1, Alix, TSG101

Для цитирования: Скрябин Г.О., Комельков А.В., Копнин П.Б., Никишин И.И., Кузьмичев С.А., Чевкина Е.М. Влияние нокдауна кавеолина-1 на белковый состав экстраклеточных везикул, секретируемых клетками немелкоклеточного рака легкого. Успехи молекулярной онкологии. 2021;8(1):41-6. DOI: 10.17650/2313-805X-20218-1-41-46.
\end{abstract}

\title{
Effect of caveolin-1 knockdown on the protein composition of extracellular vesicles secreted by non-small cell lung cancer cells
}

\section{G.O. Skryabin', A.V. Komelkov' ${ }^{1}$, P.B. Kopnin ${ }^{1}$, I.I. Nikishin' ${ }^{2}$ S.A. Kuzmichev ${ }^{1}$, E.M. Tchevkina}

${ }^{1}$ Research Institute of Carcinogenesis, N.N. Blokhin National Medical Research Center of Oncology, Ministry of Health of Russia; Build. 15, 24 Kashirskoe Shosse, Moscow 115478, Russia;

${ }^{2}$ Lomonosov Moscow State University, 1-12 Leninskie Gory, Moscow 119234, Russia

Cont a ct s: $\quad$ Elena Tchevkina tchevkina@mail.ru

Background. Recent data show evidence that lipid rafts (LR) proteins could be involved in the formation of exosomes and the sorting of proteins that make up the exosomal cargo. Such data are available for flotillins, structural and functional components of flatted rafts. The presence of the main component of caveolar rafts, caveolin-1 (Cav-1), has 
been shown in exosomes produced by some cancer cells; however, its possible participation in the regulation of the protein composition of exosomes has not been studied previously.

Materials and methods. Knockdown of Cav-1 by transduction of a lentiviral vector expressing precursors of short hairpin ribonucleic acid to Cav-1; isolation (by ultracentrifugation) and analysis (transmission electron microscopy, nanoparticle tracking analysis) of extracellular vesicles (EVs) from non-small cell lung cancer cells (NSCLC) H1299; analysis of proteins in cells and in EVs by immunoblotting.

Results. Analysis of the effect of Cav-1 expression on the composition of EV proteins associated with exosome biogenesis revealed a decrease in the level of Alix and TSG101, an increase in the level of LR proteins and the absence of changes in the level of tetraspanin CD9.

Conclusion. The obtained data demonstrate a Cav-1-dependent changes in the composition of EVs, indicating a change in the ratio of vesicles formed by the various molecular mechanisms.

Key words: exosomes, lipid rafts, flotillin, stomatin, caveolin-1, Alix, TSG101

For citation: Skryabin G.O., Komelkov A.V., Kopnin P.B., Nikishin I.I., Kuzmichev S.A., Tchevkina E.M. Effect of Caveolin-1 knockdown on the protein composition of extracellular vesicles secreted by non-small cell lung cancer cells. Uspekhi molekulyarnoy onkologii = Advances in Molecular Oncology 2021;8(1):41-6. (In Russ.). DOI: 10.17650/2313-805X2021-8-1-41-46.

\section{ВВЕДЕНИЕ}

Несмотря на растущий интерес к экзосомам как в области фундаментальных исследований, так и в контексте клинической онкологии, до сих пор молекулярные механизмы биогенеза экзосом и отбора биомолекул, входящих в их состав (экзосомального карго), изучены далеко не полностью. Процесс селекции биомолекул для включения в состав будущих экзосом неразрывно связан с процессом образования интралюминальных везикул (ИЛВ) - внутриклеточных предшественников экзосом, возникающих путем инвагинации мембран эндосом и приводящих к формированию мультивезикулярных эндосом. Предполагается, что существует несколько путей образования ИЛВ. Наиболее изученным является механизм, peализуемый с помощью комплексов, включающих в себя более 20 белков, относящихся к четырем классам ESCRT (Endosomal Sorting Complexes Required for Transport) - ESCRT-0, -I, -II и -III.

Схематично это происходит так: гетеродимер ESCRT-0 узнает убиквитинированные белки и привлекает их к мембране, формируя тем самым сортировочные микродомены (sorting microdomains) и отвечая за отбор содержимого будущей экзосомы. Кроме того, он рекрутирует комплексы ESCRT-I и -II, которые также могут связывать карго (например, ESCRT-II привлекает различные рибонуклеиновые кислоты (РНK)), но преимущественно индуцируют инвагинацию участка мембраны с выбранным «грузом». Помимо этого они привлекают каркасный белок Alix, который, в свою очередь, рекрутирует комплекс ESCRT-III, в состав которого входят белки, отвечающие за финальные этапы формирования ИЛВ - отделение сформировавшегося пузырька и диссоциацию комплекса от мембраны [1]. Маркерами данного пути биогенеза ИЛВ (и, соответственно, экзосом) считаются компоненты комплекса ESCRT, прежде всего белок TSG101 (tumor susceptibility gene 101), субъединица комплекса ESCRT. Другой механизм, не связанный, по-видимому, с уби- квитинированием молекул карго, реализуется с помощью трансмембранных белков синдекана и синтенина. Эти белки способны привлекать различные лиганды (хемокины, факторы роста, молекулы адгезии, интегрины и др.). Карго-зависимая олигомеризация синдекана и его связывание с молекулами синтенина приводят, в частности, к рекрутированию тетраспанина CD63 и белка Alix и, в конечном счете, к формированию ИЛВ [2-4]. Соответственно, каркасный белок Alix используется в качестве маркера экзосом, биогенез которых проходит с участием обоих названных механизмов. Ряд данных указывает на существование третьего, так называемого рафт-зависимого механизма, при котором основную роль в формировании ИЛВ и селекции молекул карго играют компоненты мембранных липидных микродоменов, или липидных рафтов (ЛР) [5, 6].

Этот тип сортировки карго и формирования ИЛВ изучен менее подробно и связан с изменением липидного состава эндосомальной мембраны, когда липиды кластеризуются в специфические субдомены (рафты), которые, с одной стороны, служат сборочными платформами для белковых комплексов и рекрутинга белков, с другой - вызывают инвагинацию и отпочковывание мембран с помощью процесса, инициируемого церамидом [7, 8]. Механизм сортинга экзосомального содержимого в этом случае остается малоизученным. Предполагается, что в нем могут быть задействованы тетраспанины [9] и флотиллины [10]. Описываемый путь секреции экзосом зависит от нейтральной сфингомиелазы 2-го типа (фермента, катализирующего формирование церамида) [11] и не зависит от подавления продукции компонентов комплексов ESCRT, таких как HRS, Alix или TSG101 [7].

Липидные рафты по морфологии делятся на 2 основных типа - плоские и инвагинированные (или кавеолярные). Некоторые исследователи в качестве отдельного подтипа ЛР рассматривают тетраспанин-обогащенные микродомены. Подробнее о рафт-зависимом 
пути биогенеза экзосом и участии рафт-образующих белков в этом процессе можно прочитать в обзорной статье Г.О. Скрябина и соавт. [12]. К белкам, стабилизирующим плоские ЛР, относятся представители SPFH-семейства (Stomatin, Prohibitin, Flotillin, HflK/C). Основным белком, организующим инвагинированные рафты, является кавеолин-1 (Cav-1). Учитывая сходство процессов с участием ЛР на плазматической мембране (сборка сигнальных комплексов, рафт-зависимый эндоцитоз) и мембранах эндосом (формирование ИЛВ), можно предположить, что белки ЛР задействованы в процессах биогенеза экзосом и селекции карго. Флотиллины (Flot-1, -2) неоднократно показаны в составе экзосом [13], есть данные, указывающие и на их участие в продукции экзосом и селекции экзосомального карго $[10,14]$. Предполагается, что флотиллины наряду с церамидом можно считать маркерами рафтзависимого пути биогенеза экзосом [3]. Нами впервые было показано присутствие в экзосомах и другого представителя SPFH-семейства белков плоских ЛР стоматина (Stom), более того, по ряду характеристик этот белок можно рассматривать в качестве нового экзосомального маркера [15]. Имеются данные и о присутствии в экзосомах Cav-1, и даже о связи экзосомального кавеолина с малигнизацией клеток [16], однако функциональная роль этого белка в биогенезе экзосом и селекции карго ранее не исследовалась. Целью данной работы было исследование влияния Cav-1 на состав экзосомальных белков, относящихся к различным функциональным группам и рассматриваемых в качестве маркеров различных путей биогенеза экзосом.

\section{МАТЕРИАЛЫ И МЕТОДЫ}

Культивирование клеток. Клетки немелкоклеточного рака легкого линии Н1299 культивировали в среде DMEM (ПанЭко, Россия) с добавлением 10 \% эмбриональной телячьей сыворотки (HyClone), 0,294 мг/мл L-глутамина, 0,1 мг/мл стрептомицина, 100 ед/мл пенициллина.

Выделение экстраклеточных везикул (ЭКВ). ЭКВ выделяли из кондиционированной среды после инкубации в течение 72 ч в среде DMEM с добавлением $10 \%$ эмбриональной сыворотки, очищенной от экзосом по ранее описанной методике [15].

Анализ морфологии ЭКВ. Визуализацию частиц не менее чем в 10 полях зрения проводили с использованием трансмиссионного электронного микроскопа JEM1011 (Jeol, Япония) по ранее описанной методике [15].

Характеризация наночастиц. Размер частиц и их концентрация оценивались методом анализа траекторий движения наночастиц (nanoparticle tracking analysis, NTA) с использованием прибора NanoSight LM10 (Malvern Panalytical, Великобритания) по методике, описанной нами ранее [15].

Подавление эндогенной экспрессии кавеолина-1. Последовательности малых шпилечных РНК (short hairpin RNA, shRNA), комплементарные матричной PHK Cav-1 человека, и контрольная последовательность shRNA к зеленому флуоресцентному белку (shGFP) были клонированы в вектор pLKO.1 рuго и трансдуцированы в клетки Н1299 методом лентивирусной инфекции по методике, описанной ранее [17]. В работе использовались последовательности sh 1 GCTTTG TGATTCAATCTGTAA， sh2 CCACCTTCACTG TGACGAAAT, sh3 GACCCTAAACACCTCAACGAT, sh4 GACGTGGTCAAGATTGACTTT, sh7 GACCCACT CTTTGAAGCTGTT.

Иммуноблоттинг. На 15 \% полиакриламидный гель для электрофореза наносили 20 мкг клеточного лизата и 10 мкг экзосомального белка. Анализ проводили по методике, описанной нами ранее [15]. Для гибридизации использовали следующие антитела: anti-flotillin-1 (BD, 610821), anti-caveolin-1 (BD, 610407), antistomatin (Santa Cruz Biotech, sc-134554), anti-Alix (Cell Signaling, 2171S), anti-CD9 (Cell Signaling, 13174S), antiTSG101 (Abcam, ab125011), anti- $\beta$-actin (Abcam, ab8227).

\section{РЕЗУЛЬТАТЬ}

Для подавления эндогенной экспрессии Cav-1 в клетках Н1299 использовали 5 последовательностей shRNA. Оценка эффективности нокдауна Cav-1 после лентивирусной инфекции приведена на рис. 1.

Для дальнейших экспериментов были выбраны производные сублинии Н1299 sh2Cav-1 и sh4Cav-1. Из кондиционированной среды были выделены препараты ЭКВ, которые верифицировались согласно требованиям международной ассоциации по исследованию ЭКВ (International Society for Extracellular Vesicles, ISEV) [18] методами NTA (рис. 2, $a$ ) и анализа морфологии частиц с помощью трансмиссионной электронной микроскопии (ТЭМ) (рис. 2, б).

Средний размер (105 нм, стандартное отклонение 11,7 нм) и положение максимума (73 нм), по данным NTA, находятся в диапазоне стандартных для экзосом значений. Морфология частиц (чашеобразная форма или форма «сдутых мячиков») соответствует экзосомам при визуализации методом ТЭМ.

Анализ Cav-1 показал практически полное отсутствие данного белка в экзосомах клеток с нокдауном Cav-1 (рис. 3, a).

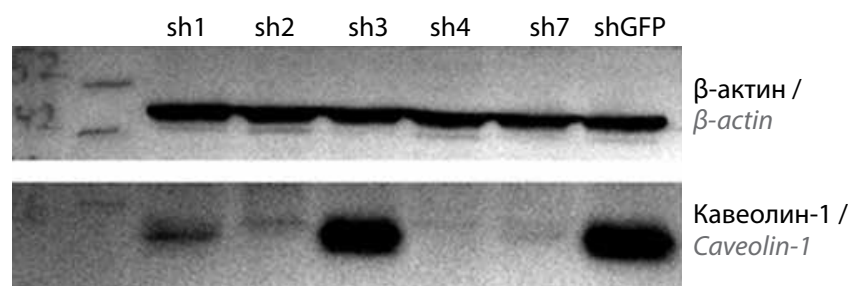

Рис. 1. Анализ экспрессии кавеолина-1 в производных клеточной линии H1299 с экспрессией shCav-1 (sh 1, sh2, sh3, sh4, sh7) и контрольной линии H1299 shGFP методом иммуноблоттинга

Fig. 1. Analysis of the expression of caveolin-1 in derivatives of $H 1299$ cell line with expression of shCav-1 (sh 1, sh2, sh3, sh4, sh 7) and the control line H1299 shGFP by immunoblotting 

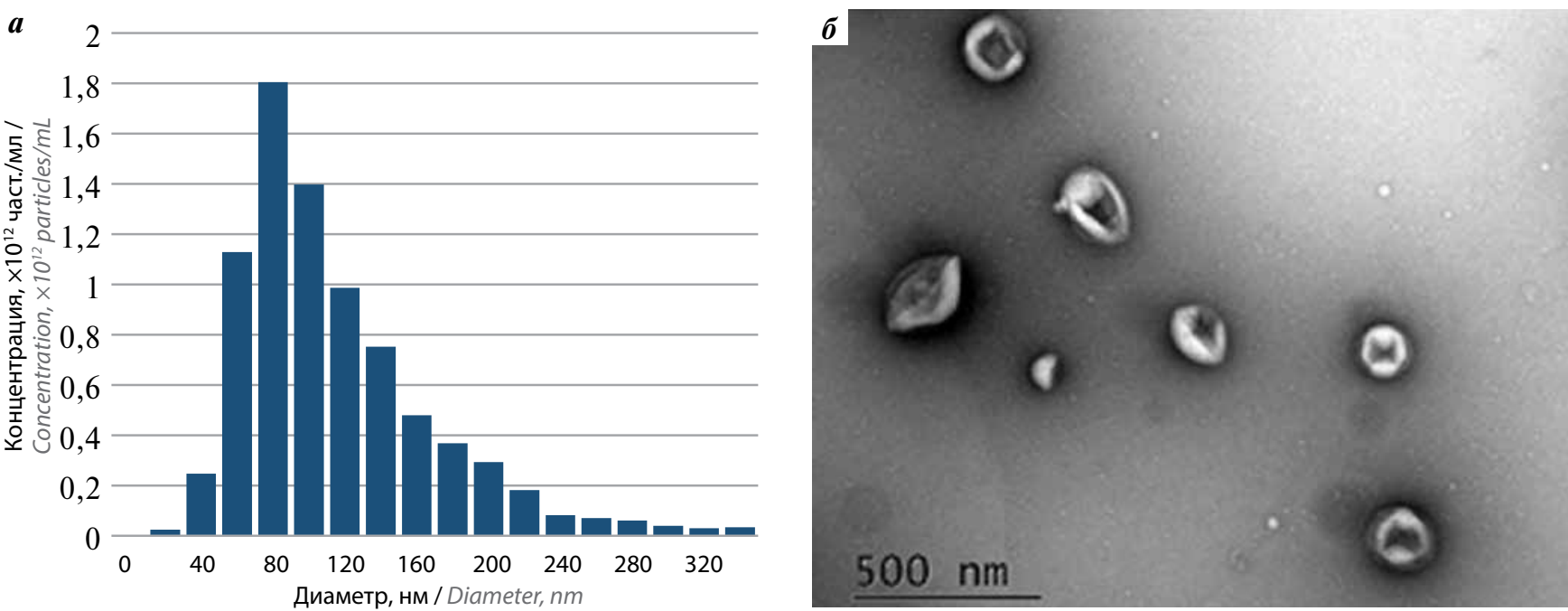

Рис. 2. Пример анализа экстраклеточных везикул для линии H1299 shGFP: a - среднечисловое размерное распределение по результатам анализа траекторий движения наночастии; б - анализ морфологии частии методом трансмиссионной электронной микроскопии (на фото приведен маситабный отрезок 500 нм)

Fig. 2. An example of extracellular vesicles analysis for H1299 shGFP cells: a - number-average size distribution based on nanoparticle tracking analysis results; $b$ - analysis of particle morphology by transmission electron microscopy (the photo shows a scale bar of $500 \mathrm{~nm}$ )

$\boldsymbol{a}$

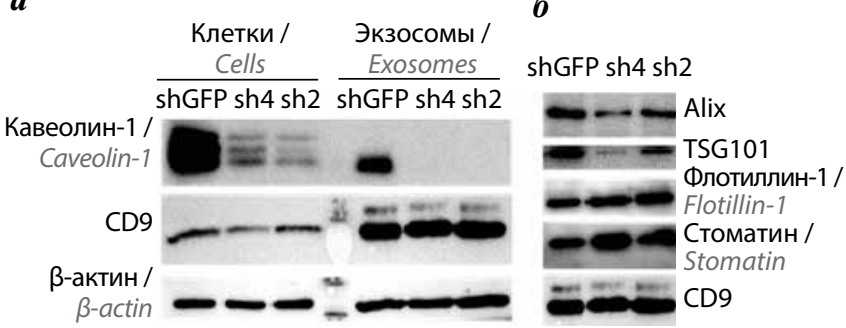

Рис. 3. Анализ уровня представленности белков в экстраклеточных везикулах, секретируемых клетками H1299 с нокдауном Cav-1 (sh2 и sh4) и клетками контрольной линии H1299 shGFP; в качестве референсных белков использованы $\beta$-актин (для клеток) и CD9 (для экзосом): $a$ - анализ экспрессии Саv-1 в клетках и экзосомах; 6 - анализ белков липидных рафтов, флотиллина-1 и стоматина, а также белков Alix и TSG101 в экзосомах

Fig. 3. Analysis of the protein levels in extracellular vesicles secreted by H1299 cells with Cav-1 knockdown (sh2 and sh4) and the control line H1299 shGFP; $\beta$-actin (for cells) and CD9 (for exosomes) were used as reference proteins: $a$ - analysis of Cav-1 expression in cells and exosomes; $b$ - analysis of lipid raft proteins flotillin-1 and stomatin, as well as Alix and TSG101 proteins in exosomes

Далее в препаратах экзосом был проведен анализ белков, ассоциированных с биогенезом экзосом, включая тетраспанин CD9, предположительно участвующий во всех путях биогенеза экзосом [19], белок Alix, участвующий в ESCRT- и синдекан/синтенинзависимых механизмах [3], TSG-101, ассоциированный с ESCRT-зависимым механизмом [3], и белки ЛР семейства SPFH: флотиллин-1, ассоциированный с рафт-зависимым путем [10], и стоматин, белок ЛР, предложенный нами ранее в качестве экзосомального маркера [15]. На рис. 3, б представлен репрезентатив- ный пример результатов иммуноблоттинга, полученных в одном эксперименте с использованием единой мембраны для возможности адекватного сравнения уровня исследуемых белков. Как видно на рис. 3 , 6 , нокдаун Cav-1 никак не отразился на уровне «общего» экзосомального маркера CD9, при этом уровень белков ЛР увеличился, а белков, ассоциированных с «нерафтовыми» путями биогенеза экзосом, - снизился по сравнению с контролем.

\section{ЗАКЛЮЧЕНИЕ}

В работе исследовалось влияние Cav-1 на уровень белков, ассоциированных с различными механизмами биогенеза экзосом, а также рафт-образующего белка плоских ЛР, стоматина, ранее предложенного нами в качестве нового экзосомального маркера [15] в ЭКВ, секретируемых клетками немелкоклеточного рака легких. Мы показали, что подавление экспрессии Cav-1 в клетках Н1299 привело к снижению в ЭКВ уровня белков, ассоциированных с «не-рафтовыми» путями биогенеза экзосом, таких как Alix и TSG-101, и к повышению уровня рафтовых белков флотиллина-1 и стоматина. При этом уровень тетраспанина CD9, «универсального» маркера экзосом, предположительно, задействованного во всех молекулярных сценариях биогенеза экзосом, в ЭКВ, секретируемых клетками с нокдауном Cav-1, остался прежним. Полученные данные демонстрируют Cav-1-зависимое изменение состава ЭКВ, свидетельствующее об изменении соотношения везикул, образованных с участием различных молекулярных механизмов. 


\section{$\begin{array}{lllllllllllllllllllll}Л & И & \text { T } & \text { E } & \text { P } & \text { A } & \text { T } & \text { У } & \text { P } & \text { A } & \text { I } & \text { R } & \text { E } & \text { F } & \text { E } & \text { R } & \text { E } & \text { N } & \text { C } & \text { E } & S\end{array}$}

1. Soung Y.H., Nguyen T., Cao H. et al. Emerging roles of exosomes in cancer invasion and metastasis. BMB Rep 2016;49(1):18-25. DOI: 10.5483/BMBRep.2016.49.1.239.

2. Baietti M.F., Zhang Z., Mortier E. et al. Syndecan-syntenin-ALIX regulates the biogenesis of exosomes Nat Cell Biol 2012;14(7):677-85. DOI: $10.1038 /$ ncb2502

3. Villarroya-Beltri C., Baixauli F., Gutiérrez-Vázquez C. et al. Sorting it out: regulation of exosome loading. Semin Cancer Biol 2014;28(1):3-13. DOI: 10.1016/j.semcancer.2014.04.009.

4. Kowal J., Tkach M., Théry C. Biogenesis and secretion of exosomes. Curr Opin Cell Biol 2014;29(1):116-25. DOI:10.1016/j.ceb.2014.05.004.

5. Lingwood D., Simons K. Lipid rafts as a membrane-organizing principle. Science 2010;327(5961):46-50. DOI: $10.1126 /$ science. 1174621.

6. Simons K., Sampaio J.L. Membrane organization and lipid rafts. Cold Spring Harb Perspect Biol 2011;3(10):1-17. DOI:10.1101/ cshperspect.a004697.

7. Trajkovic K., Hsu C., Chiantia S. et al. Ceramide triggers budding of exosome vesicles into multivesicular endosomes. Science 2008;319(5867):1244-7. DOI: $10.1126 /$ science. 1153124 .

8. Stuffers S., Sem Wegner C., Stenmark H., Brech A. Multivesicular endosome biogenesis in the absence of ESCRTs.
Traffic 2009;10(7):925-37. DOI: 10.1111/j.1600-0854.2009.00920.x.

9. van Niel G., Charrin S., Simoes S. et al. The tetraspanin CD63 regulates ESCRTindependent and -dependent endosomal sorting during melanogenesis. Dev Cell 2011;21(4):708-21.

DOI: 10.1016/j.devcel.2011.08.019.

10. Phuyal S., Hessvik N.P., Skotland T. et al. Regulation of exosome release by glycosphingolipids and flotillins. FEBS J 2014;281(9):2214-27. DOI: $10.1111 /$ febs. 12775 .

11. Yuyama K., Sun H., Mitsutake S., Igarashi Y. Sphingolipid-modulated exosome secretion promotes clearance of amyloid- $\beta$ by microglia. $\mathrm{J}$ Biol Chem 2012;287(14):10977-89. DOI: $10.1074 / \mathrm{jbc} . M 111.324616$.

12. Скрябин Г.О., Комельков А.В., Савельева Е.Е., Чевкина Е.М. Липидные рафты в биогенезе экзосом. Биохимия 2020;85(2):208-24. [Skryabin G.O., Komelkov A.V., Savelyeva E.E., Tchevkina E.M. Lipid rafts in exosome biogenesis. Biohimiya $=$ Biochemistry (Moscow) 2020;85(2):208-24. (In Russ.)].

13. Théry C., Clayton A., Amigorena S., Raposo G., Isolation and characterization of exosomes from cell culture supernatants and biological fluids. Curr Protoc Cell Biol 2006;30(1):3.22.1-9. DOI: 10.1002/0471143030.cb0322s30.

14. Kajimoto T., Okada T., Miya S. et al. Ongoing activation of sphingosine 1-phosphate receptors mediates maturation of exosomal multivesicular endosomes. Nat Commun 2013;4:2712. DOI: $10.1038 /$ ncomms3712.

15. Skryabin G.O., Komelkov A.V., Galetsky S.A. et al. Stomatin is highly expressed in exosomes of different origin and is a promising candidate as an exosomal marker. J Cell Biochem 2021;122(1):100-15. DOI: $10.1002 / j c b .29834$.

16. Campos A., Salomon C., Bustos R. et al. Caveolin-1-containing extracellular vesicles transport adhesion proteins and promote malignancy in breast cancer cell lines. Nanomedicine 2018;13(20): 2597-609.

DOI: 10.2217/nnm-2018-0094.

17. Kainov Y., Favorskaya I., Delektorskaya V. et al. CRABP1 provides high malignancy of transformed mesenchymal cells and contributes to the pathogenesis of mesenchymal and neuroendocrine tumors. Cell Cycle 2014;13(10):1530-9. DOI: $10.4161 /$ cc. 28475.

18. Thery C., Lavieu G., Martin-Jaular L. et al. Minimal information for studies of extracellular vesicles 2018 (MISEV2018): a position statement of the International Society for Extracellular Vesicles and update of the MISEV2014 guidelines. J Extracell Vesicles 2018;7(1):1535750.

19. Yanez-Mo M., Barreiro O., GordonAlonso M. et al. Tetraspanin-enriched microdomains: a functional unit in cell plasma membranes. Trends Cell Biol 2009;19(9):434-46. DOI: $10.1016 /$ j.tcb.2009.06.004.

\section{Вклад авторов:}

Г.О. Скрябин: получение клеточных линий с нокдауном кавеолина-1, выделение экстраклеточных везикул (ЭКВ), анализ белков, анализ ЭКВ методом анализа траекторий движения наночастиц (Nanoparticles tracking analysis, NTA);

А.В. Комельков: анализ данных NTA, трансмиссионная электронная микроскопия (ТЭМ), денситометрия;

П.Б. Копнин: получение генно-инженерных конструктов;

И.И. Никишин: анализ ЭКВ методом ТЭМ;

С.А. Кузьмичев: анализ литературы, анализ NTA;

Е.М. Чевкина: дизайн исследования, анализ результатов, написание статьи. Authors' contributions:

G.O. Skryabin: knockdown of caveolin-1, isolation of extracellular vesicles (EVs), protein analysis, analysis of EVs by nanoparticle tracking analysis (NTA);

A.V. Komelkov: analysis of NTA and transmission electron microscopy (TEM) data, densitometry;

P.B. Kopnin: development of vectors for caveolin-1 knockdown;

I.I. Nikishin: TEM analysis of EVs;

S.A. Kuzmichev: analysis of literature data, NTA analysis;

E.M. Tchevkina: research design, analysis of results, article writing.

ORCID aвTоров / ORCID of authors

Скрябин Г.O. / G.O. Skryabin: https://orcid.org/0000-0002-4127-6973

Комельков А.В. / A.V. Komelkov: https://orcid.org/0000-0003-0766-163X

Копнин П.Б. / Р.В. Kopnin: https://orcid.org/0000-0002-2078-4274

Никишин И.И. / I.I. Nikishin: https://orcid.org/0000-0002-4071-7693

Кузьмичев С.A. / S.A. Kuzmichev: https://orcid.org/0000-0003-1660-0898

Чевкина E.M. / E.M. Tchevkina: https://orcid.org/0000-0001-8837-7969 
Конфликт интересов. Авторы заявляют об отсутствии конфликта интересов.

$\sim$ Conflict of interest. The authors declare no conflict of interest.

Финансирование. Исследование проведено при поддержке Российского фонда фундаментальных исследований (проект № 18-04-00038А).

Financing. The study was performed with the support of Russian Foundation for Basic Research (project No. 18-04-00038A). 